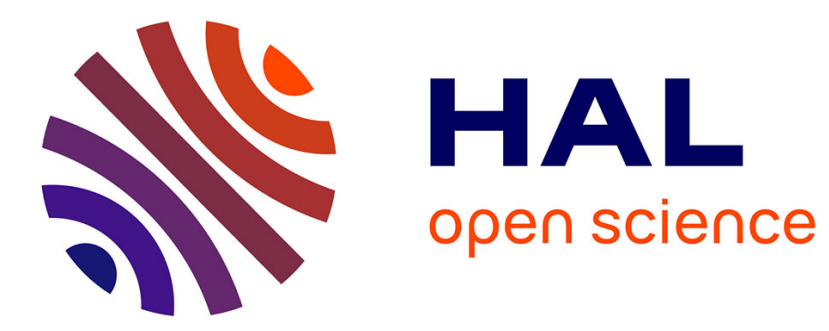

\title{
Borehole water level model for photovoltaic water pumping systems
}

\author{
T. Vezin, Simon Meunier, Loic Queval, J.A. A Cherni, L. Vido, Arouna \\ Darga, Philippe Dessante, P.K. K Kitanidis, Claude Marchand
}

\section{- To cite this version:}

T. Vezin, Simon Meunier, Loic Queval, J.A. A Cherni, L. Vido, et al.. Borehole water level model for photovoltaic water pumping systems. Applied Energy, 2020, 258, pp.114080. 10.1016/j.apenergy.2019.114080 . hal-03582268

\section{HAL Id: hal-03582268 \\ https://hal.science/hal-03582268}

Submitted on 21 Feb 2022

HAL is a multi-disciplinary open access archive for the deposit and dissemination of scientific research documents, whether they are published or not. The documents may come from teaching and research institutions in France or abroad, or from public or private research centers.
L'archive ouverte pluridisciplinaire HAL, est destinée au dépôt et à la diffusion de documents scientifiques de niveau recherche, publiés ou non, émanant des établissements d'enseignement et de recherche français ou étrangers, des laboratoires publics ou privés. 


\title{
Borehole water level model for photovoltaic water pumping systems
}

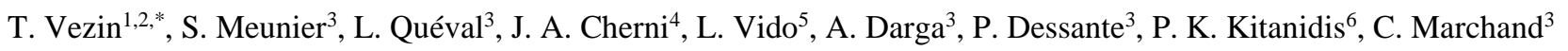 \\ ${ }^{1}$ Department of Physics, Ecole Polytechnique, Palaiseau, France \\ ${ }^{2}$ DargaTech SARL, Ouagadougou, Burkina Faso \\ ${ }^{3}$ GeePs | Group of electrical engineering -Paris, CNRS, CentraleSupélec, Univ. Paris-Sud, Univ. Paris-Saclay, \\ Sorbonne Université, Gif-sur-Yvette, France \\ ${ }^{4}$ Centre for Environmental Policy, Imperial College London, London, United Kingdom \\ ${ }^{5}$ SATIE | Laboratory of Systems \& Applications of Information \& Energy Technologies, Univ. de Cergy-Pontoise, \\ Cergy-Pontoise, France \\ ${ }^{6}$ Department of Civil and Environmental Engineering, Stanford University, Stanford, United States \\ *Corresponding author. Thomas Vezin: Email address: thomas.vezin.x15@polytechnique.edu
}

Declaration of interest: none.

Keywords: Photovoltaic water pumping; Groundwater resources; Data validated model; Sensitivity analysis; Optimal sizing; Lifecycle cost

\section{Highlights:}

- A borehole water level model for photovoltaic water pumping systems is developed.

- The model is validated against experimental data and has an accuracy of $97 \%$.

- The model allows us to study the influence of water resources on the system sizing.

- The influence of the static water level on the optimal lifecycle cost is about $11 \%$.

- The influence of the drawdown on the optimal lifecycle cost is lower than $2 \%$.

\begin{abstract}
Using photovoltaic energy to pump water from aquifers is an interesting solution to circumvent the low electricity grid coverage and provide improved domestic water access in off-grid areas in sub-Saharan Africa. When pumping and during the lifetime of a pumping installation, the borehole water level changes, which impacts the amount of energy required to extract water from the aquifer. In order to address alterations in energy requirements, this article, develops a data-driven borehole water level model adapted to photovoltaic water pumping systems (PVWPS). The proposed model is applicable to all types of PVWPS and aquifers. It has been validated against experimental data from a pilot PVWPS located in a rural off-grid village in Burkina Faso having achieved more than $97 \%$ accuracy. Thanks to this borehole model, we have been able to assess the influence of the variability of groundwater resources on both the performance of PVWPS and on their optimal sizing. We show that the variation of the static water level can require a increase of the peak power of the PV modules of up to $100 \%$. Nonetheless, the effect of the drawdown due to the pumping is negligible. This study can help companies, governments and non-governmental organizations to better take into account the variability and the sustainability of groundwater resources in the optimal sizing and monitoring of PVWPS.
\end{abstract}




\begin{tabular}{|c|c|}
\hline$H_{p 1}(t)$ & Additional head due to pressure losses in pipe $1(\mathrm{P} 1)(\mathrm{m})$ \\
\hline$T_{a}(t)$ & Ambient temperature $\left({ }^{\circ} \mathrm{C}\right)$ \\
\hline$H_{b, d}(t)$ & Borehole dynamic water level (m) \\
\hline$H_{b, s}$ & Borehole static water level $(\mathrm{m})$ \\
\hline$H_{b}(t)$ & Borehole water level (m) \\
\hline$Q_{c}(t)$ & Collected flow rate $\left(\mathrm{m}^{3} \cdot \mathrm{s}^{-1}\right)$ \\
\hline$H_{t, r}$ & Height between the bottom of the tank and the start level of the controller $(\mathrm{m})$ \\
\hline$H_{t, s}$ & Height between the bottom of the tank and the stop level of the controller (m) \\
\hline$H_{t, b}$ & Height between the ground level and the bottom of the tank (m) \\
\hline$H_{m p}$ & Height between the ground level and the position of the motor-pump (m) \\
\hline$H_{t, i}$ & Height between the ground level and the water entry in the tank (m) \\
\hline$G_{p v}(t)$ & Irradiance on the plane of the PV modules $\left(\mathrm{W} . \mathrm{m}^{-2}\right)$ \\
\hline LCC & Lifecycle cost of the PVWPS (USD) \\
\hline$L V C$ & Lifecycle variable cost of the PVWPS (USD) \\
\hline$M P$ & Motor-pump reference \\
\hline$\kappa_{n}$ & $n^{\text {th }}$ aquifer loss coefficient $\left(\mathrm{m}^{-2} . \mathrm{s}\right)$ \\
\hline$\mu_{n}$ & $n^{\text {th }}$ borehole loss coefficient $\left(\mathrm{m}^{-5} \cdot \mathrm{s}^{2}\right)$ \\
\hline OPEX & Operational cost of the PVWPS (USD) \\
\hline$P_{p v}(t)$ & Power produced by the PV modules $(\mathrm{W})$ \\
\hline$Q_{p}(t)$ & Pumped flow rate $\left(\mathrm{m}^{3} \cdot \mathrm{s}^{-1}\right)$ \\
\hline$P_{p v, p}$ & PV modules peak power $\left(\mathrm{W}_{\mathrm{p}}\right)$ \\
\hline$b(t)$ & Start/stop signal from the controller \\
\hline$H_{t}(t)$ & Tank water height $(\mathrm{m})$ \\
\hline$T D H(t)$ & Total dynamic head $(\mathrm{m})$ \\
\hline CAPEX & Variable capital cost of the PVWPS (USD) \\
\hline$V_{t}$ & Volume of the tank $\left(\mathrm{m}^{3}\right)$ \\
\hline
\end{tabular}

\section{Introduction}

In Sub-Saharan Africa, 600 million people do not have access to electricity, mainly in rural areas [1]. Photovoltaic energy is a suitable alternative for providing the essential energy services in these off-grid areas [2]. Water pumping systems powered by photovoltaic energy have notably proved to be an interesting solution to improve domestic water access [3], [4]. Indeed, they are economically competitive in off-grid areas [5], [6], have low maintenance cost [7] and do not emit greenhouse gases during operation [8].

Several models are available to simulate the performance of photovoltaic water pumping systems (PVWPS). Nonetheless, only a few of them include a borehole model to simulate the variations of the water level in the borehole during the operation of the PVWPS and throughout its lifetime. Taking into account these variations is of crucial importance because they impact the amount of energy required to extract water from the aquifer and may therefore affect the performances of the energy conversion system and the global efficiency of the energy conversion chain [9], [10]. Of the few existing borehole models, some are empirical and assume a drawdown either linear in the pumped flow rate [11], [12], quadratic [13], [14], or both [15]. Despite that these approaches are simple and generic, the empirical models have not been validated by comparing the simulated water level in the borehole to experimental measurements. Another often-used approach is to use an analytical expression derived from the Theis equation [16]. This approach has mostly been implemented to study PVWPS for irrigation [9], [17], and was compared against experimental data [18]. However it relies on several assumptions that are rarely met (i.e., radial flow in a confined, homogenous and isotropic aquifer, sinusoidal pumping), which limits its range of application and accuracy.

Various authors have undertaken sensitivity analyses on the influence of groundwater resources on PVWPS performance and optimal sizing. They have studied the influence of the pumping head on PVWPS optimal sizing [19], efficiency [20], and daily pumped volume [10], [21]. A further study has reported that pressure losses in the pipes can entail a variation of the necessary peak power of the photovoltaic (PV) modules of 10\% [22]. However, these works have neglected the drawdown, which corresponds to the drop of the water level in the borehole while pumping. To our knowledge, only one study investigated the effect of the drawdown [23]. Yet, it only tested 4 values for each parameter and the range of variation chosen for the parameters was not justified. In addition, no cross sensitivity analysis was performed, although all the borehole parameters - i.e., static water level and drawdown coefficients - may vary at once. 
In this article, we present a generic and empirical borehole model adapted to PVWPS. In contrast to the previous borehole models, ours does not rely on Theis equation and is validated against experimental data. Because the identified borehole parameters cannot be known exactly due to estimation errors and time variation of the parameters, we perform an extensive literature review to present a plausible range of uncertainty on these parameters. We then undertake a sensitivity and crosssensitivity analysis on the influence of the borehole parameters on the PVWPS model output and the optimal sizing of such systems. This study is useful to assess the importance of borehole models for PVWPS modeling. This knowledge will lead to better sized and more affordable PVWPS and thus improve water access across rural sub-Saharan Africa.

The PVWPS model is described in Section 2. The borehole model used and its validation against experimental data are presented in Section 3. In Section 4, we study the range of uncertainty of the borehole parameters. Finally, we present the influence of their variation on the PVWPS model output and on its optimal sizing in Section 5.

\section{Photovoltaic water pumping system}

\subsection{Architecture}

The PVWPS architecture considered in this article is presented in Figure 1. It is a common architecture for PVWPS for domestic water access. It encompasses the following components:

- PV modules.

- A motor-pump with a maximum power point tracking (MPPT) controlled inverter that is immersed in the borehole. This whole set is called "motor-pump" in the rest of the article.

- A controller that stops and starts the motor-pump according to the water height in the tank, obtained by a float switch.

- A water tank.

- A pipe (P1) that connects the motor-pump to the tank.

- A fountain where inhabitants collect water.

- Another pipe (P2) that connects the tank to the fountain.

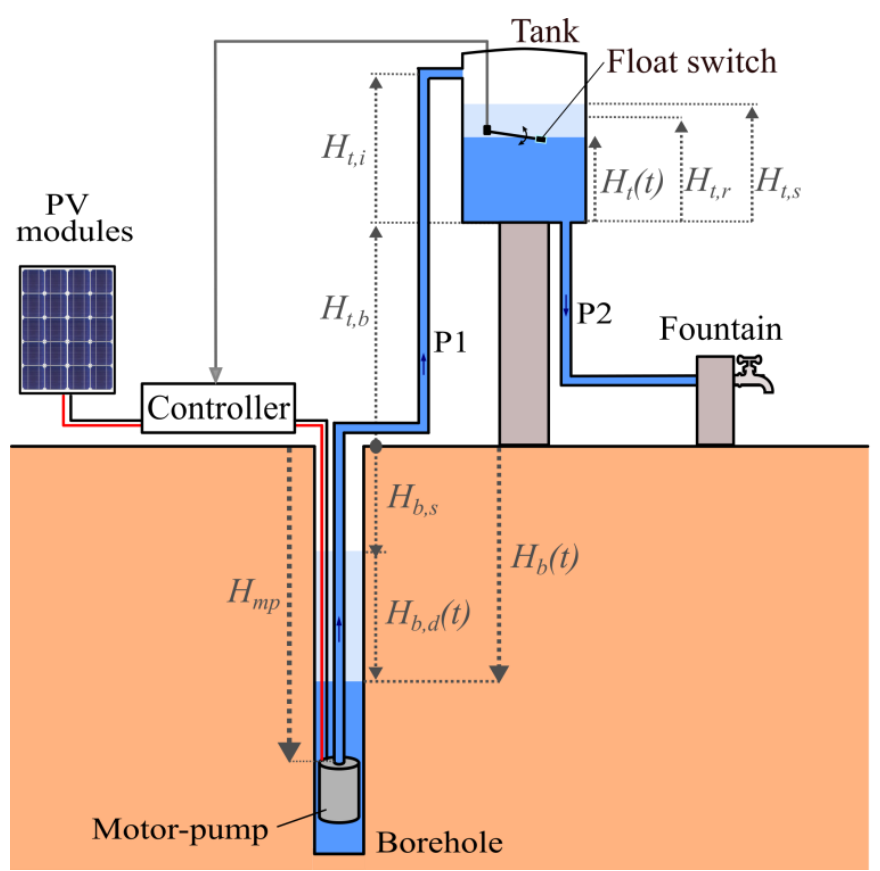

Figure 1: Architecture of the system and definition of the heights.

The height datum is set at the ground level so $H_{b, s}, H_{b, d}(t), H_{b}(t)$ and $H_{m p}$ are negative.

\subsection{Model}

The block diagram of the PVWPS model is presented in Figure 2. The PVWPS model inputs are the irradiance on the plane of the PV modules $G_{p v}$, the ambient temperature $T_{a}$ and the collected flow rate at the fountain $Q_{c}$. Its output is the water level in the tank $H_{t}$. The modeling of the electromechanical sub-system has been presented in details in [15]. The modeling of the borehole is the focus of this article. 


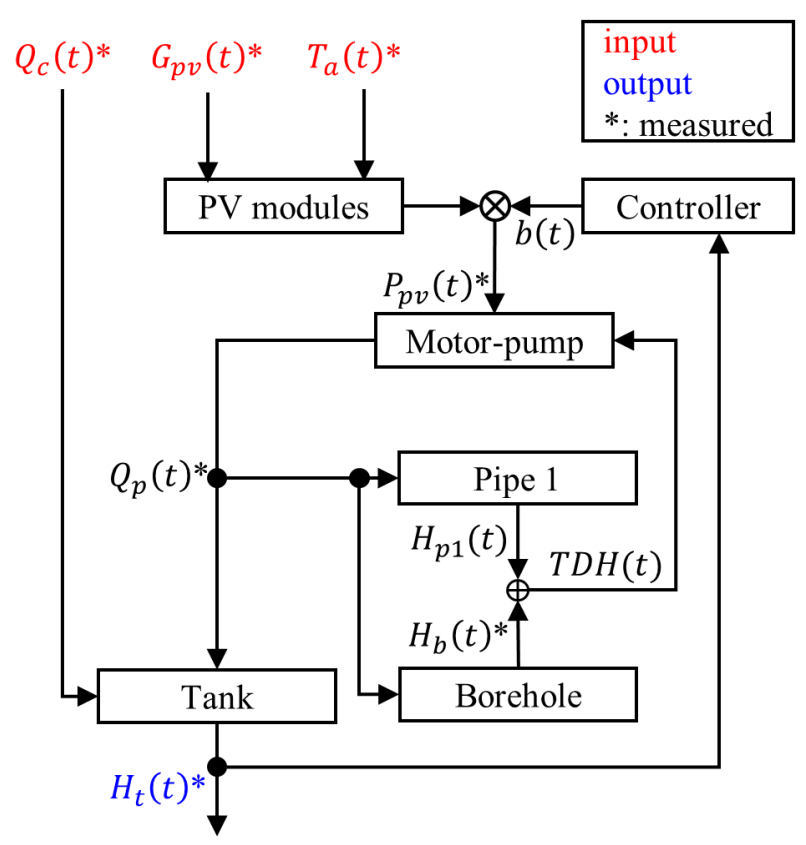

Figure 2: Block diagram of the PVWPS model.

$t$ : time, $Q_{c}$ : collected flow rate, $G_{p v}$ : irradiance on the plane of the $P V$ modules, $T_{a}$ : ambient temperature, $P_{p v}$ : input power to the motor-pump, $Q_{p}$ : pumped flow rate, TDH: total dynamic head, $H_{t}$ : tank water height, $H_{b}$ : borehole water level,

$H_{p 1}$ : hydraulic losses in pipe $1, b$ : start/stop signal from the controller.

\subsection{Experimental setup}

In order to validate the model of the PVWPS, and more particularly the borehole model, data have been collected on a PVWPS for domestic water access located in Gogma, Burkina Faso (see Figure 3). A video of the village and the PVWPS is available at https://youtu.be/VrjM0edKVsI. In this system, there are $620 \mathrm{~W}_{\mathrm{p}}$ of multi-crystalline PV modules, a motor-pump SQFlex 5A-7 [24] and a cylindrical steel tank of $11.4 \mathrm{~m}^{3}$. The quantities measured on this system are specified in Figure 2. We have monitored the ambient temperature $T_{a}$, the irradiance on the plane of the PV modules $G_{p v}$, the collected flow rate at the fountain $Q_{c}$, the power produced by the PV modules $P_{p v}$, the pumped flow rate $Q_{p}$ with a data logger that we had developed [15]. These quantities have been recorded with a time step of $2 \mathrm{~s}$ since February 2018. An hydrostatic pressure sensor (DCX-22 SG [25]) has been added to the setup in February 2019 to monitor the borehole water level $H_{b}$ with a time step of 1 minute. For convenience, all the measured data were rescaled to an equally spaced temporal resolution of $1 \mathrm{~min}$ by nearest interpolation. In addition, references [15] and [26] showed that a temporal resolution of $1 \mathrm{~min}$ is sufficient for the modelling and optimal sizing of PVWPS for domestic water access.

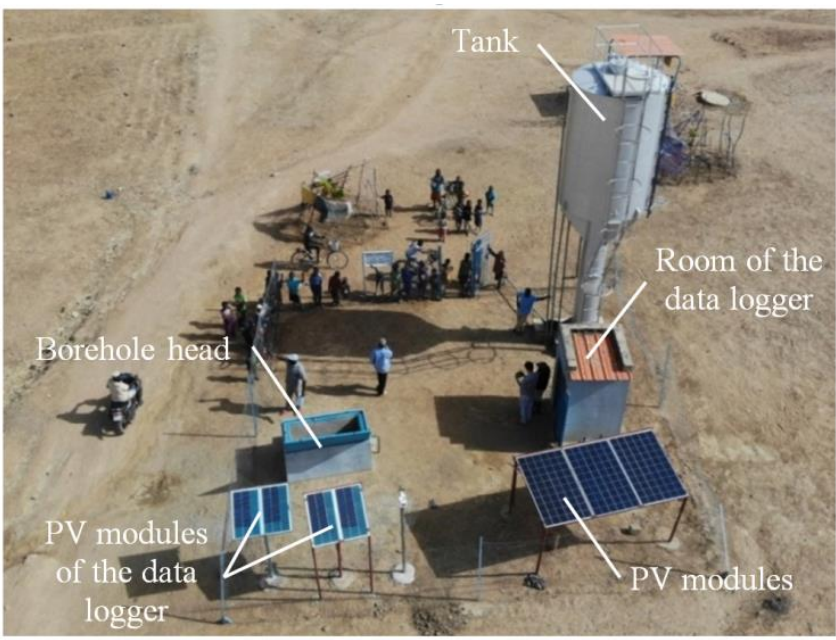

Figure 3: Picture of the PVWPS in the village of Gogma, Burkina Faso.

Figure 4 shows a sample of the measured quantities relevant to our study. The comparison between Figure $4 \mathrm{c}$ and Figure $4 \mathrm{e}$ confirms that there is a clear relation between the pumped flow rate $Q_{p}$ and the borehole water level $H_{b}$. Note that the 
response of the borehole to pumping is fast. For instance, at 1:18 PM on the $11^{\text {th }}$ of April, when pumping resumes at a pumped flow rate of $1.010^{-3} \mathrm{~m}^{3} \cdot \mathrm{s}^{-1}$, the borehole water level goes from $-7.6 \mathrm{~m}$ to $-10.5 \mathrm{~m}$ in $8 \mathrm{~min}$.

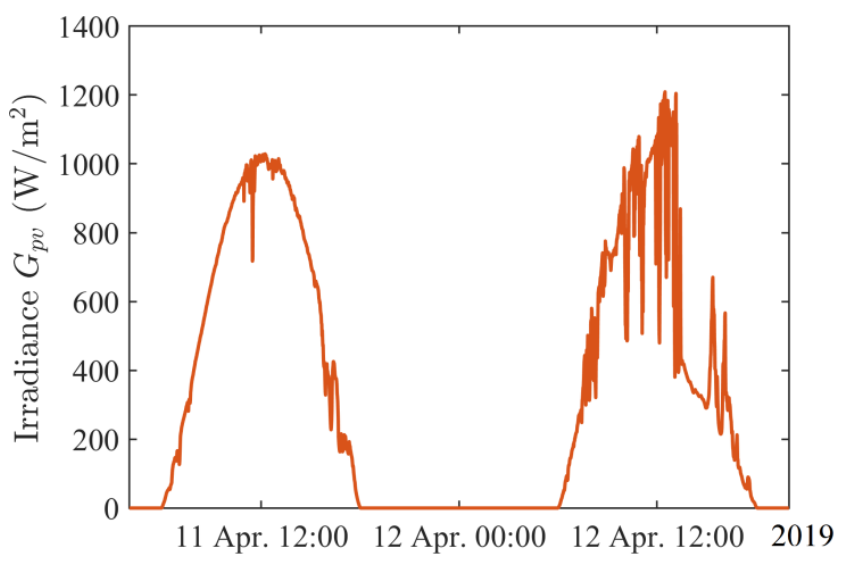

(a)

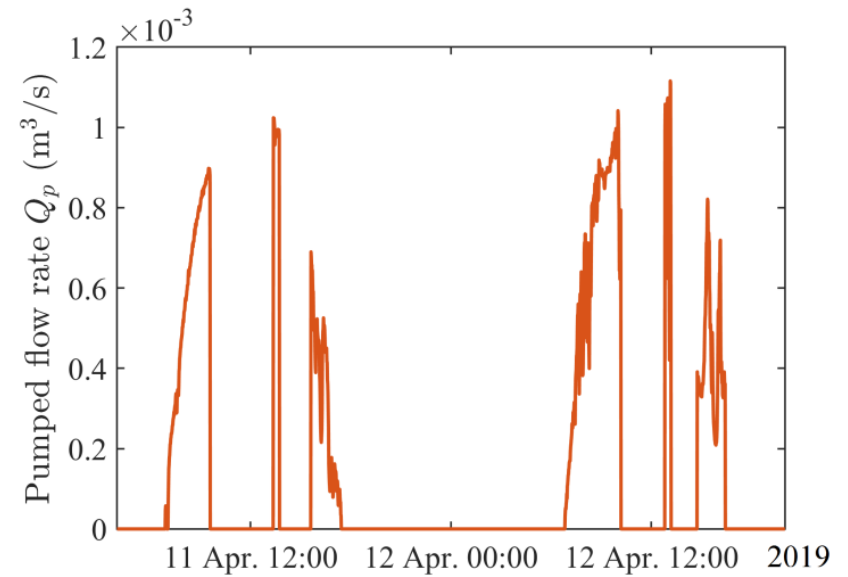

(c)

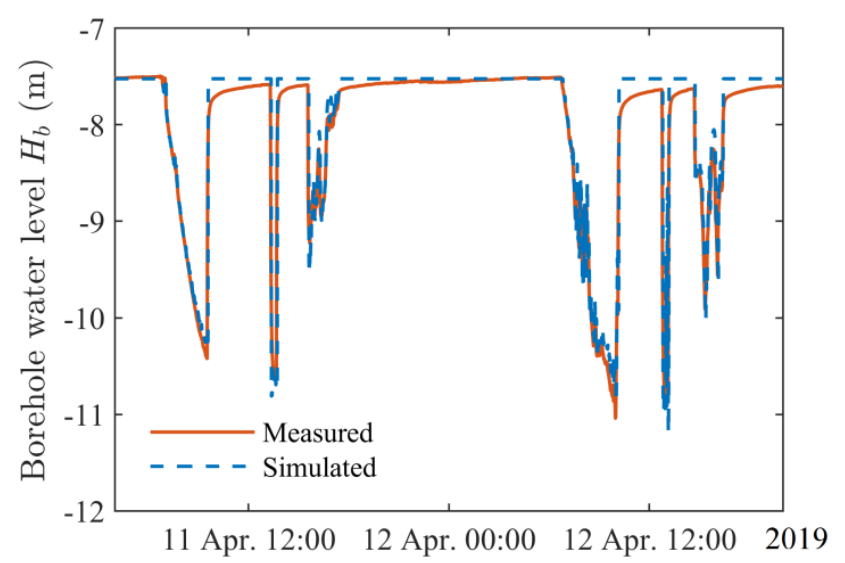

(e)

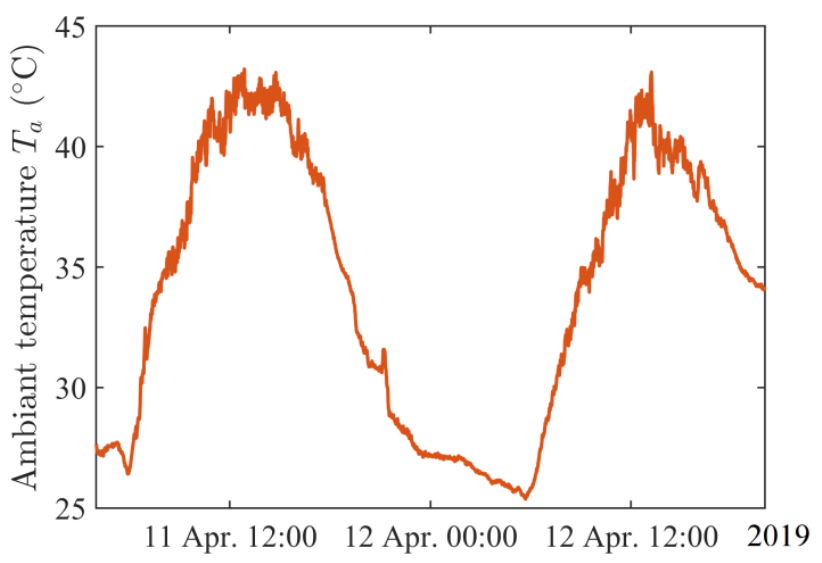

(b)

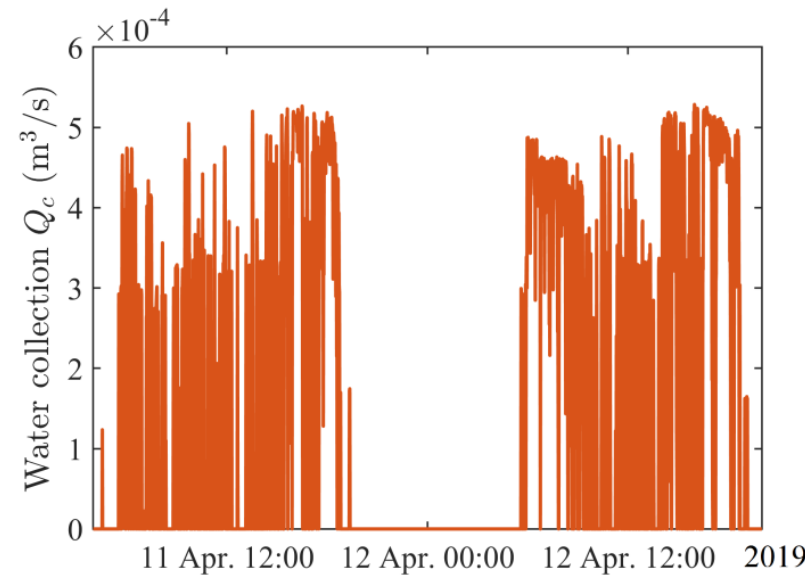

(d)

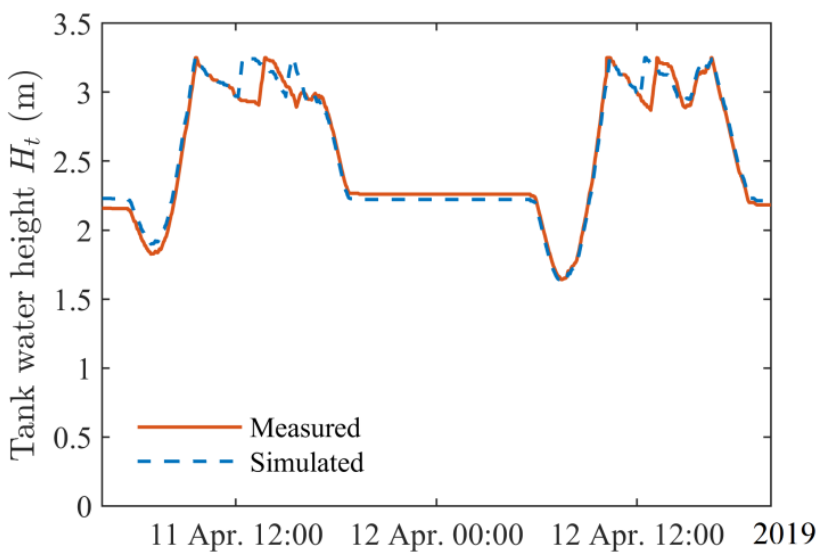

(f)

Figure 4: Sample of the experimental data and of the corresponding simulation results.

\section{Data validated borehole model}

In this section, we focus on the borehole model. The input of this model is the pumped flow rate $Q_{p}(t)$, and its output is the borehole water level $\mathrm{H}_{b}(t)<0$. The latter is the sum of the static borehole water level $H_{b, s}$ (i.e. the water level in the borehole when there is no pumping, $\left.H_{b, s}<0\right)$ and of the dynamic borehole water level $H_{b, d}(t)$ (i.e. the drawdown due to the pumping, $\left.H_{b, d}(t)<0\right)$ :

$$
H_{b}(t)=H_{b, s}+H_{b, d}(t)
$$




\subsection{Generic borehole model}

The borehole model presented here is a generalization of Jacob's equation [27]. It considers that the drawdown $H_{b, d}$ changes linearly and quadratically with the pumped flow rate [28] and that the drawdown at a time $t$ also depends on the pumped flow rates at previous times [29]. The borehole water level is therefore given by:

$$
H_{b}(t)=H_{b, s}-\sum_{n=0}^{N} \kappa_{n} Q_{p}(t-n \Delta T)-\sum_{n=0}^{N} \mu_{n} Q_{p}(t-n \Delta T)^{2}
$$

where $\kappa_{n}(>0)$ are aquifer losses coefficients, $\mu_{n}(>0)$ are borehole losses coefficients and $\Delta T$ is the characteristic response time of the borehole. $N$ is a fitting parameter that represents the effect of the past flows on the borehole water level. Its value is chosen based on available data using valid statistical methods [30].

\subsection{Parameters identification and validation}

The application of this model to the PVWPS of Gogma is composed of two phases: identification and validation. Firstly, we identify the coefficients of equation (2) by using the measured values of the pumped flow rate $Q_{p}$ and of the borehole water level $H_{b}$ for the "identification period", which we define as ranging from the $1^{\text {st }}$ to the $7^{\text {th }}$ of April 2019 . The coefficient of determination, i.e. the square of the multiple correlation coefficient $\left(R^{2}\right)$, is used to characterize the goodness of the fit. Secondly, we validate the model by comparing the simulated borehole water level $H_{b}$ and the simulated tank water height $H_{t}$ to the measurements for the "validation period", which lasts from the $8^{\text {th }}$ to the $21^{\text {st }}$ of April 2019. To quantify the quality of the model, we compute the normalized root mean square error between the measured values $H_{\text {meas }}$ and the simulated values $H_{\text {sim }}$,

$$
N R M S E=\sqrt{\frac{\sum_{i=1}^{n}\left(H_{\text {meas }}(i)-H_{\text {sim }}(i)\right)^{2}}{\sum_{i=1}^{n} H_{\text {meas }}(i)^{2}}}
$$

where $n$ is the number of points in the validation period. This approach is data-driven since the parameters of the model are identified from experimental data obtained with specific sensors. It is an approach that suits our modern era because sensors are available at a low price. But, as we will see in Section 5, monitoring permanently the borehole water level is not always required, and it may be possible to extract the values of the parameters directly from the pumping tests that follow every borehole drilling [31].

To use the borehole model of equation (2), one first needs to specify the values of $N$ and $\Delta T$. We start by considering a simple model with $N=0$ which will be justified in the last paragraph of this section. Equation (2) becomes:

$$
H_{b}(t)=H_{b, s}-\kappa_{0} Q_{p}(t)-\mu_{0} Q_{p}(t)^{2}
$$

We perform the identification of the 3 parameters of the borehole model $\left(H_{b, s}, \kappa_{0}, \mu_{0}\right)$ and the validation of the corresponding model. The results are summarized in Table 1. The NRMSE on the borehole water level is $2.5 \%$ and the NRMSE on the tank water height is $5.3 \%$. The simulated borehole water level and tank water height have been added to Figure $4 \mathrm{e}$ and Figure $4 \mathrm{f}$ to illustrate the goodness of the model.

We then consider the case $N=1$. To do so, we need to define the characteristic response time of the borehole $\Delta T$. From the observed relaxation of the borehole when the pumping stops (see Figure 4b), we consider that $\Delta T$ lies between $10 \mathrm{~min}$ and $60 \mathrm{~min}$. For 6 values of $\Delta T$, we perform the identification of the 5 parameters of the borehole model $\left(H_{b, s}, \kappa_{0}, \mu_{0}, \kappa_{1}, \mu_{1}\right)$ and the validation of the resulting model. The results are shown in Table 1 . The value of $R^{2}$ is the same as for the model with $N=0$ and the NRMSE on the validation period has not improved much. This means that the additional parameters $\left(\kappa_{1}, \mu_{1}\right)$ have low statistical significance. We also considered more parameters $(N=2,3)$ but the results were not significantly improved either. This was expected since the model with $N=0$ is already very accurate. The reason why we only need the first coefficients in this application of the model is that the response of the borehole in Gogma is fast (see Section 2.3). For aquifers with a slower response, following coefficients $\left(\kappa_{1}, \mu_{1}, \kappa_{2}, \mu_{2}, \ldots\right)$ may be required to achieve a satisfying accuracy. In that case, one can follow the methodology presented in this section to determine the number of terms needed and their values. 
Table 1: Results for the identification of the borehole model coefficients for $N=0$ and $N=1$.

Light blue denotes the nominal parameters of the model.

\begin{tabular}{|c|c|c|c|c|c|c|c|}
\hline \multirow{2}{*}{$\frac{\mathrm{N}}{\Delta T(\min )}$} & \multirow[t]{2}{*}{$\mathbf{0}$} & \multicolumn{6}{|c|}{1} \\
\hline & & 10 & 20 & 30 & 40 & 50 & 60 \\
\hline$H_{b, s}(\mathrm{~m})$ & -7.5 & -7.5 & -7.5 & -7.5 & -7.5 & -7.5 & -7.5 \\
\hline$\kappa_{0}\left(\mathrm{~m}^{-2} . \mathrm{s}\right)$ & $2.4 \times 10^{3}$ & $2.1 \times 10^{3}$ & $2.2 \times 10^{3}$ & $2.3 \times 10^{3}$ & $2.3 \times 10^{3}$ & $2.4 \times 10^{3}$ & $2.4 \times 10^{3}$ \\
\hline$\mu_{0}\left(\mathrm{~m}^{-5} \cdot \mathrm{s}^{2}\right)$ & $8.4 \times 10^{5}$ & $8.3 \times 10^{5}$ & $8.6 \times 10^{5}$ & $8.1 \times 10^{5}$ & $7.6 \times 10^{5}$ & $7.3 \times 10^{5}$ & $7.3 \times 10^{5}$ \\
\hline$\kappa_{1}\left(\mathrm{~m}^{-2} \cdot \mathrm{s}\right)$ & - & $2.7 \times 10^{2}$ & $2.1 \times 10^{2}$ & $1.8 \times 10^{2}$ & $1.6 \times 10^{2}$ & $1.5 \times 10^{2}$ & $1.4 \times 10^{2}$ \\
\hline$\mu_{1}\left(\mathrm{~m}^{-5} \cdot \mathrm{s}^{2}\right)$ & - & 0 & 0 & 0 & 0 & 0 & 0 \\
\hline$R^{2}$ & 0.99 & 0.99 & 0.99 & 0.99 & 0.99 & 0.99 & 0.99 \\
\hline$N R M S E$ on $H_{b}(\%)$ & 2.5 & 2.5 & 2.4 & 2.4 & 2.3 & 2.3 & 2.4 \\
\hline$N R M S E$ on $H_{t}(\%)$ & 5.3 & 5.3 & 5.3 & 5.3 & 5.3 & 5.3 & 5.3 \\
\hline
\end{tabular}

Thus, in this case study, the simple borehole water level model $(N=0)$ succeeded in predicting both the water level and the water height in the tank with adequate accuracy. This validates the borehole model for the PVWPS of Gogma.

\section{Uncertainty on the parameters}

We identified two sources of uncertainty when selecting the values of the borehole model. The first one is the "estimation error" made when inferring the value of the parameters (as done in the previous section for example). The second is the "time variation" of the parameters over the lifetime of the PVWPS (typically 20 years). These uncertainties need to be taken into account when sizing the system or evaluating its performances. To obtain a realistic range of uncertainty for the borehole parameters $\left(H_{b, s}, \kappa_{0}, \mu_{0}\right)$, we undertook a literature review. The results are presented in Section 4.1 and 4.2, and were adapted to the specific case of rural sub-Saharan Africa.

\subsection{Estimation error}

We identified two different methods to estimate the borehole parameters: direct observation and identification. A direct observation involves a "measurement error". For example, one could use a water level meter to measure the static water level $H_{b, s}$ with a small error $\left( \pm 10^{-2} \mathrm{~m}[32]\right)$. Unfortunately, there are no direct measurement methods known for the drawdown coefficients $\left(\kappa_{0}, \mu_{0}\right)$. An identification - i.e. a statistical estimation - leads to an "identification error". The usual procedure to determine $\kappa_{0}$ and $\mu_{0}$ is to perform a regression using the data of the step-drawdown test performed right after the drilling of the borehole [31]. For sets of data commonly found in the literature, the resulting standard error (SE) on each parameters, $\kappa_{0}$ and $\mu_{0}$, is about $15 \%$ [15], [33], [34]. As far as the static water level $H_{b, s}$ is concerned, direct measurement methods are more common, but few identification methods exist. For instance, the method proposed in [15] consists of a retro-fitting of the motor-pump characteristic curve and leads to a SE of $0.4 \%$ when performed with the data set of our case study. The typical estimation errors are summarized in Table 2.

Table 2: Typical estimation errors on the borehole parameters.

\begin{tabular}{|c|c|c|c|}
\hline \multicolumn{4}{|c|}{ "NA" stands for "not applicable". } \\
\hline $\begin{array}{c}\text { Measurement } \\
\text { error }\end{array}$ & $\pm 10^{-2} \mathrm{~m}$ & $\mathrm{NA}$ & $\mathrm{NA}$ \\
\hline $\begin{array}{c}\text { Identification } \\
\text { error }\end{array}$ & $\pm 1 \%$ & $\pm 15 \%$ & $\pm 15 \%$ \\
\hline
\end{tabular}

Of course, the latter "identification error" depends on the identification method used, as well as the type of data available. For instance, to the best of our knowledge, we performed the first identification of the borehole parameters using a hydrostatic pressure sensor in Section 3.2. The quality and the quantity of the data used allowed us to significantly reduce the SE on the parameters: we obtained $0.01 \%$ on $H_{b, s}, 0.4 \%$ on $\kappa_{0}$ and $1.5 \%$ on $\mu_{0}$.

\subsection{Time variation}

Regarding time variation of the static water level $H_{b, s}$, three different timescales were identified. First, there can be a "seasonal" variation over the course of a single year, between the wet and dry season [35]-[38]. Second, there can be an "annual" variation of the static water level $H_{b, s}$ between wet and dry years [35], [36], [39]. Third, there can be "secular" 
trend over the course of the years, which is usually imputable to the exploitation of the aquifer [35], [40], [41]. The depletion of the aquifer can be avoided by limiting the exploitation of the aquifer to sustainable levels, though global climate change may also contribute to aquifer depletion [42].

Note that the values found in the literature for the time variation of the static water level $H_{b, s}$ can be extremely large. The seasonal variation can reach $20 \mathrm{~m}$ [35], but such large values are due to large pumping capacities leading to large seasonal variation in the water demand. The secular variation can reach $100 \mathrm{~m}$ [35], but only in the case of an overexploited aquifer. In the case study of Gogma - and more generally in rural sub-Saharan Africa - such levels of pumping are not yet achieved [43]. Therefore, we will not take such large values into account and consider that the secular variations are limited to $10 \mathrm{~m}$ and that the order of magnitude of seasonal variations is $1 \mathrm{~m}$.

Regarding $\kappa_{0}$ and $\mu_{0}$, the main identified source of variation over time is the clogging of the borehole due to biomass accumulation, mineral deposits or re-arrangement of the sand particles of the borehole [44], [45]. Though there are methods to reverse the clogging [45], [46], the monitoring of the borehole which can diagnose such a problem is scarcely done in these regions. This may cause a dramatic increase of the drawdown over the years, up to $3000 \%$, though most of the values found were below $180 \%$ [45]. Time variations of the considered parameters are summarized in Table 3 . We observe that uncertainties linked to time variations are more prominent than the ones linked to estimation errors.

Table 3: Typical time variation of the borehole parameters over different time scales.

"ND" stands for "no data".

\begin{tabular}{|c|c|c|c|}
\hline & $\boldsymbol{H}_{\boldsymbol{b}, \boldsymbol{s}}$ & $\boldsymbol{\kappa}_{\mathbf{0}}$ & $\boldsymbol{\mu}_{\mathbf{0}}$ \\
\hline Seasonal & $\pm 1 \mathrm{~m}$ & $\mathrm{ND}$ & $\mathrm{ND}$ \\
\hline Annual & $\pm 3 \mathrm{~m}$ & $\mathrm{ND}$ & $\mathrm{ND}$ \\
\hline Secular & $-10 \mathrm{~m}$ & $+180 \%$ & $+180 \%$ \\
\hline
\end{tabular}

\section{Sensitivity analysis}

In this section, the values of the parameters $\left(H_{b, s}, \kappa_{0}, \mu_{0}\right)$ obtained from the identification of Section 3.2 are referred to as "nominal values" of the parameters and are written with the superscript "nom". The results shown on the figures are computed on the "validation period", from the $8^{\text {th }}$ to the $21^{\text {st }}$ of April (dry season). To verify the robustness of our results, we computed the same quantities from the $24^{\text {th }}$ of June to the $7^{\text {th }}$ of July, which falls during the wet season.

\subsection{Range of variation of the parameters}

Before performing the sensitivity analysis, we need to select a range of variation for each borehole parameters. To do so, we consider all the uncertainties listed in the previous section (see Table 2 and Table 3) and add them to obtain a maximum plausible range of variation of the borehole parameters. Thus, for the case study of Gogma, we estimate that $H_{b, s}$ can vary from 0.5 to 2.9 times its nominal value and that the drawdown coefficients $\left(\kappa_{0}, \mu_{0}\right)$ can vary from 0.85 to 3 times their nominal values. For convenience, we choose the same range of variation for every parameters for our sensitivity analysis. They will thus vary from 0 to 3 times its nominal value (see Table 4).

Table 4: Selected range of variation for each borehole parameter.
\begin{tabular}{|c|c|c|c|}
\hline & $\boldsymbol{H}_{\boldsymbol{b}, \boldsymbol{s}}$ & $\boldsymbol{\kappa}_{\mathbf{0}}$ & $\boldsymbol{\mu}_{\mathbf{0}}$ \\
\hline $\begin{array}{c}\text { Nominal } \\
\text { values } \\
\left(\boldsymbol{X}^{\text {nom }}\right)\end{array}$ & $-7.5 \mathrm{~m}$ & $2.4 \times 10^{3} \mathrm{~m}^{-2} . \mathrm{s}$ & $8.4 \times 10^{5} \mathrm{~m}^{5} . \mathrm{s}^{2}$ \\
\hline $\begin{array}{c}\text { Uncertainty } \\
\text { estimated } \\
\text { from } \\
\text { literature }\end{array}$ & -14 to $+4 \mathrm{~m}$ & -15 to $+195 \%$ & -15 to $+195 \%$ \\
\hline $\begin{array}{c}\text { Selected } \\
\text { range of } \\
\text { variation }\end{array}$ & 0 to $3 H_{b, s}^{\text {nom }}$ & 0 to $3 \kappa_{0}^{\text {nom }}$ & 0 to $3 \mu_{0}^{\text {nom }}$ \\
\hline
\end{tabular}




\subsection{Influence on model output}

We can now perform a sensitivity analysis on the borehole parameters. To do so, we change the value of one parameter at a time within its selected range of variation, while the others are kept to their nominal value. For each combination, we compute the NRMSE between the simulated tank water height and the one obtained with the nominal value of the parameter. The results are shown in Figure 5.

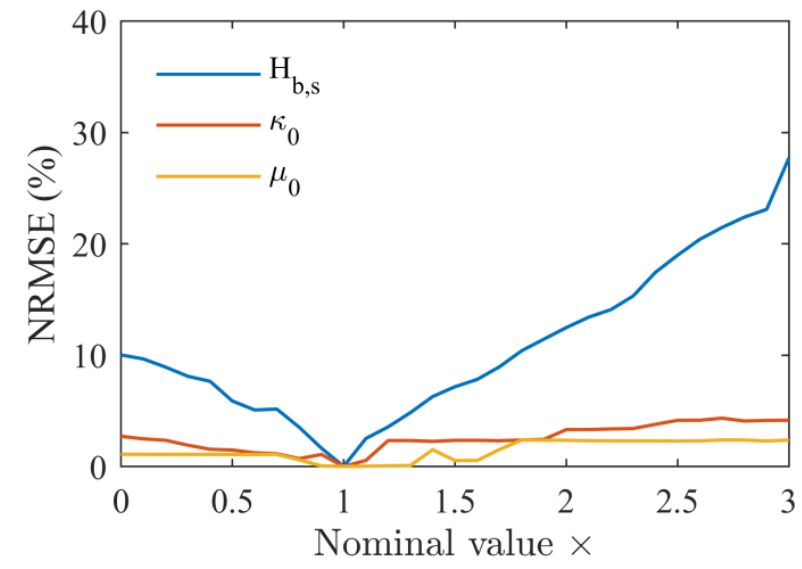

Figure 5: Sensitivity on the NRMSE on the tank water height.

We observe in Figure 5 that borehole parameters $\left(H_{b, s}, \kappa_{0}, \mu_{0}\right)$ influence the NRMSE on the tank water height. Indeed, they modify the water level in the borehole $H_{b}$ and therefore the pumped flow rate $Q_{p}$ for a given input power to the motor-pump. We also observe that $\kappa_{0}$ and $\mu_{0}$ have a small influence $(<5 \%)$ on the water height in the tank $H_{t}$ compared to the influence of $H_{b, s}$ (which can reach 30\%). This result can be explained by looking at Equation (4). For a pumped flow rate $Q_{p}$ of $10^{-3} \mathrm{~m}^{3} . \mathrm{s}^{-1}$, if we set $H_{b, s}$ to twice its nominal value, the borehole water level decreases by $7.5 \mathrm{~m}$. In comparison, doubling $\kappa_{0}$ entails a decrease of the borehole water level of $2.3 \mathrm{~m}$ and doubling $\mu_{0}$ decreases it by $0.8 \mathrm{~m}$.

Next, we perform a cross-sensitivity analysis to study the mutual influence of the borehole pararmeters on the $N R M S E$ on the tank water height. To do so, we allow the three parameters to vary simultaneously and independently in a specific range, from 1 to $x$ times their nominal value. For each triplet $\left(H_{b, s}, \kappa_{0}, \mu_{0}\right) \in[1, x]^{3}$, we compute the $N R M S E$ on the tank water height $H_{t}$. We then select the maximum NRMSE encountered within this range, and plot it as a function of $x$. The results are shown in Figure 6. This profile is almost the same as the profile of the NRMSE when only $H_{b, s}$ varies (see Figure 5). Thus, no multiplicative effect is observed.

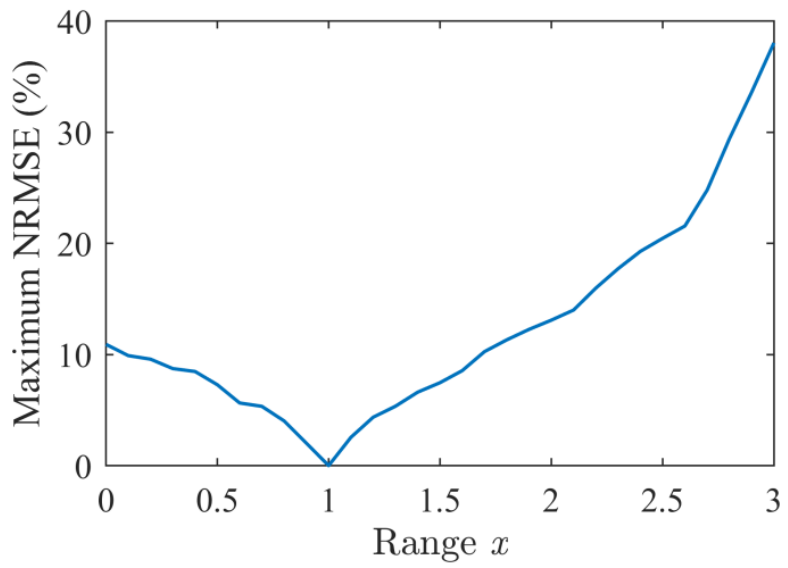

Figure 6: Cross sensitivity on the NRMSE on the tank water height.

\subsection{Influence on optimal sizing}

In this section, we study the effect of the variation of the borehole parameters on the optimal sizing of the PVWPS. Firstly, we define the optimization scheme. Secondly, we perform the sensitivity analysis on the optimal sizing of the PVWPS. 


\subsubsection{Optimal sizing}

The variables of the optimization are the peak power of the PV modules, $P_{p v, p}$, the volume of the steel tank, $V_{t}$ and the motor-pump reference, $M P$. We have digitized the characteristic curves of 8 submersible SQFlex motor-pumps from Grundfos that are suitable for PVWPS [47].

The objective function is the lifecycle variable cost $(L V C)$ of the PVWPS in $\mathrm{k} \$$ [48]. It is given by [3]:

$$
L V C=C A P E X+\sum_{j=1}^{L} \frac{O P E X(j)}{(1+r)^{j}}
$$

where the variable capital cost $C A P E X$ is given by:

$$
C A P E X=0.00086 P_{p v, p}+C(M P)+0.62 V_{t}
$$

and the operational cost $O P E X$ is given by:

$$
\operatorname{OPEX}(j)=\left\{\begin{array}{c}
\frac{C A P E X}{100} \text { if } j \neq 10 \\
\frac{C A P E X}{100}+C(M P) \text { if } j=10
\end{array}\right.
$$

where $L=20$ years [49]-[51] is the lifetime of the PVWPS, $r=5.6 \%$ [52] is the discount rate and $C(M P)$ is the cost of the motor-pump MP [47]. We consider that the operational cost of the system is equal to $1 \%$ of the CAPEX every year [3], plus a replacement of the motor-pump every 10 years [48]. The coefficients in equations (6) and (7) have been obtained by fitting data provided by companies located in Burkina Faso [48]. Note that we do not include the fixed costs (prospecting, borehole drilling, fountain installation, workforce) in the objective function since they have no impact on the optimization results. In the case study of Gogma, these fixed costs are equal to $20 \mathrm{k} \$$ [48].

The constraints of the optimization are:

1. The tank water height must remain positive in order to meet the needs of the inhabitants:

$$
H_{t}(t)>0, \forall t
$$

2. The borehole water level must remain above the position of the motor-pump $\left(H_{m p}=-30 \mathrm{~m}\right)$ :

$$
H_{b}(t)>H_{m p}, \forall t
$$

3. The total dynamic head must remain smaller than the maximum hydraulic head $H_{\max }$ of the motor-pump $M P$ :

$$
T D H(t)<H_{\max }(M P), \forall t
$$

A differential evolution algorithm is used to find the optimal PVWPS size [53]. This stochastic algorithm belongs to the category of evolutionary algorithms which are commonly used to solve non linear optimization problems [54]. We implemented the algorithm presented in reference [53] in MatLab. Since the motor-pump reference $M P$ is a discrete optimization variable, we perform one optimization for each motor-pump reference and keep the best result as final result of the optimization.

First of all, we perform the optimization for the nominal values of the borehole parameters. The corresponding $L V C$ and the associated values of the optimization var iables are summarized in Table 5, with the superscript "ref" standing for "reference". These values can be compared to the existing size of the system in Gogma : $P_{p v, p}=620 \mathrm{~W}_{\mathrm{p}}$, $M P=\mathrm{SQFlex} 5 \mathrm{~A} 7, V_{t}=11.4 \mathrm{~m}^{3}$, which is associated to a $L V C$ of $13.9 \mathrm{k} \$$ [15]. This shows that the current PVWPS is oversized.

Table 5: Optimal sizing for the nominal values of the borehole parameters.

\begin{tabular}{|c|c|}
\hline Parameter & Value \\
\hline$L V C^{r e f}$ & $7.1 \mathrm{k} \$$ \\
\hline$P_{p v, p}^{r e f}$ & $6.2 \times 10^{2} \mathrm{~W}_{\mathrm{p}}$ \\
\hline$M P^{\text {ref }}$ & SQFlex $2.5-2$ \\
\hline$V_{t}^{r e f}$ & $4.1 \mathrm{~m}^{3}$ \\
\hline
\end{tabular}




\subsubsection{Effect of the variation of the parameters on the optimal sizing}

For the sensitivity analysis on the optimal sizing, we perform the optimization while varying $H_{b, s}, \kappa_{0}$ and $\mu_{0}$ one at a time. We then compute the normalized error with respect to the reference value $\left(\Delta X=\frac{X-X^{r e f}}{X^{r e f}}\right)$ for the output of the optimization $(L V C)$ and for the continuous optimization variables $\left(P_{p v, v}\right.$ and $\left.V_{t}\right)$. We also give the motor-pump reference selected by the algorithm for each optimization. The results are shown in Figure 7. It is interesting to note that the algorithm always selects the SQFlex 2.5-2 motor-pump.

While the variations of $H_{b, s}$ alone can lead to a $10 \%$ change of $L V C$, the contributions of $\kappa_{0}$ and $\mu_{0}$ are negligible. Similarly to the results on the model output (see Section 5.2), $H_{b, s}$ has much more influence on the PVWPS optimal sizing than $\kappa_{0}$ and $\mu_{0}$. Figure $7 \mathrm{~b}$ also shows that large variations of $H_{b, s}$ may require to increase the PV modules peak power $P_{p v, p}$ by up to $100 \%$. In contrast, the volume of the tank $V_{t}$ is not strongly afected $(<10 \%)$ by the variations of the static water level. This is consistent with the fact that the price of PV modules (9\% of the optimal LVC in the "reference" case) is relatively low compared to the price of the tank ( $41 \%$ of the optimal $L V C$ in the "reference" case). This result may be compared to the one of reference [22], which showed that pressure losses in the pipe $P_{1}$ (see Figure 1) could add up to $10 \%$ of the necessary peak power of the PV modules. This suggest that the effect of the static water level is much higher (about 8 times) that the one of the pressure losses on the PVWPS sizing.

In a first approach, we suggest that manufacturers take the influence of the change of the static water level into account by designing systems that can support an extension of the PV peak power $P_{p v, p}$ after a few years if necessary. For instance they could choose a controller and a pump that can support an increase of $P_{p v, p}$. But given that the variable lifecycle cost $L V C$ represents only $26 \%$ of the total lifecycle cost $(L C C)$, a variation of $10 \%$ of $L V C$, triggered by the change in the static water level $H_{b, s}$, will impact the $L C C$ by less than $3 \%$. Thus another solution for manufacturers is the oversize the system by the correct amount during the design phase. This would allow them to sell a system that would not need to be changed in case of large variations of groundwater resources. 


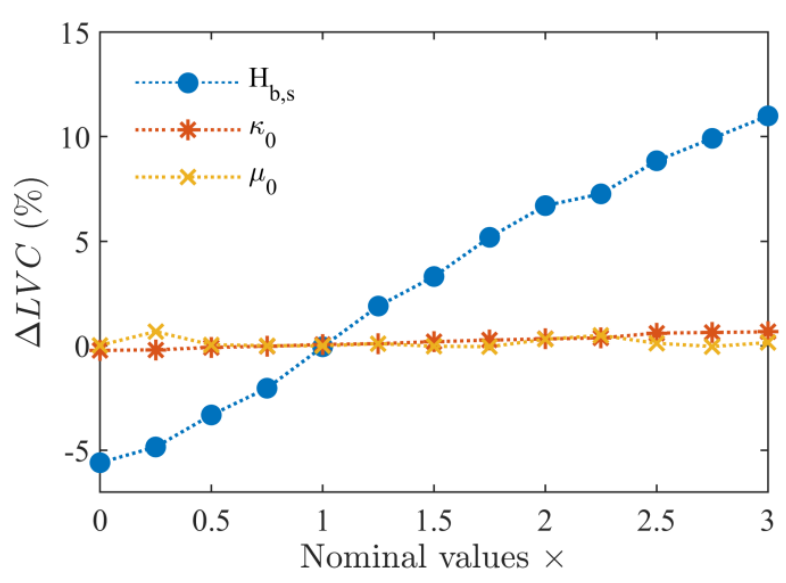

(a)

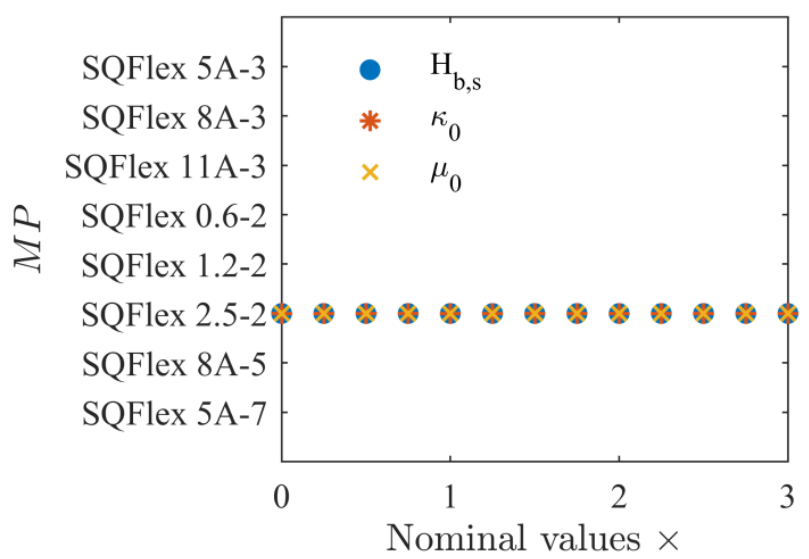

(c)

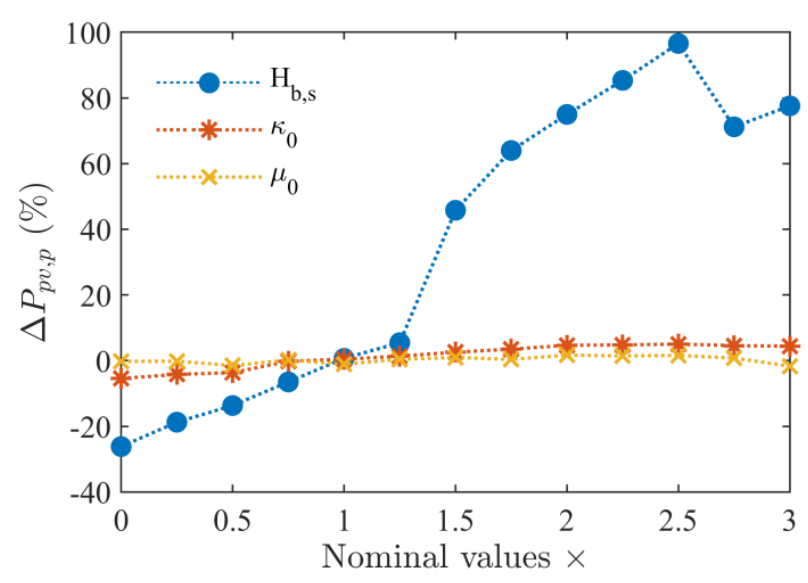

(b)

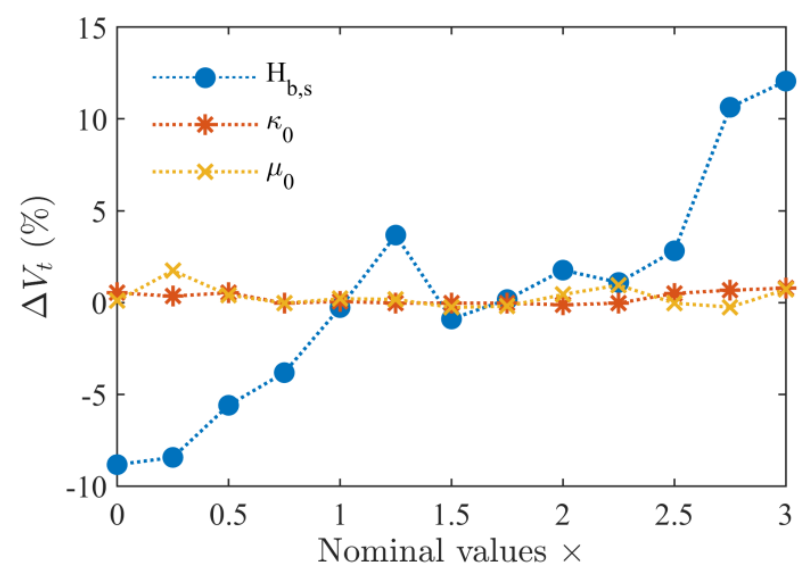

(d)

Figure 7: Sensitivity on the PVWPS optimal sizing.

We also studied the cross sensitivity of the optimization with respect to the borehole parameters by varying simultaneously $H_{b, s}, \kappa_{0}$ and $\mu_{0}$. This allows us to study the mutual influence of those parameters. As presented in Section 5.2 , we specify a range (from 1 to $x$ ) in which the three borehole parameters can vary simultaneously and idependently. We then compute the maximum $\triangle L V C$ obtained in this range. The results are shown in Figure 8. Comparison with Figure 7 a shows that there is no multiplicative effect for the optimization results either. This information is of prime importance because it means that the recommendations we made based on Figure 7 still hold if all the borehole parameters vary at the same time and in the worst possible way.

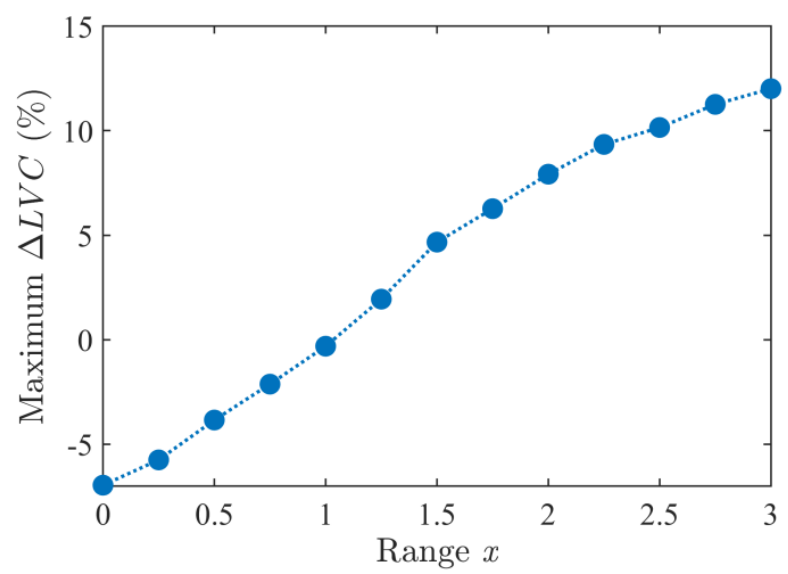

Figure 8: Cross sensitivity on the optimal LVC

\subsection{Discussion}

The above resultss show that, though they can vary by $200 \%$ (see section 5.1), the influence of $\kappa_{0}$ and $\mu_{0}$ on the PVWPS model output and its optimal sizing is almost negligible. Therefore, a precise estimate of the drawdown coefficients 
$\left(\kappa_{0}, \mu_{0}\right)$ is not necessary in the frame of PVWPS for domestic water access. They can be identified from the results of the pumping tests that occur after the drilling of the borehole (error of $\pm 15 \%$ on the identification).

The only parameter with a significant importance is the static water level $H_{b, s}$. We showed that if the PVWPS is sized according to measurements performed during the first year ("reference" case), the PVWPS may become undersized in the future due to variations of $H_{b, s}$ over its lifetime. To avoid such an undersizing, we suggest to perform - before the sizing and depending on the location - a preliminary study on the current and projected exploitation of the aquifer. This would help understanding how much the static water level $H_{b, s}$ may change over time. This also means that $H_{b, s}$ should be estimated with the highest precision available and monitored through the lifetime of the PVWPS, once a year for instance. Fortunately, there exist many cost-effective methods to do so, such as water level meters [32], which can be rented for about $15 \$$ per day even in rural communities such as Gogma.

\section{Conclusion}

In this study, we presented a data-driven borehole water level model that is suitable for photovoltaic water pumping systems. Contrary to most borehole models in the literature, it is generic and can be applied to any kind of PVWPS and aquifer. The proposed model was validated using experimental measurements of the borehole water level and the tank water height of a PVWPS installed in a rural off-grid village of Burkina Faso.

Such model made it possible to assess the influence of groundwater resources on the output of the PVWPS model and on the PVWPS optimal sizing by performing a sensitivity analysis. We showed that the most significant parameter is the static water level in the borehole. It is responsible for variations of the model output of up to $30 \%$ for a variation of the parameter of $200 \%$ (see Figure 5) and can entail an over-or under-sizing of the system. In comparison, drawdown coefficients were responsible for variations of the output of only 4 or $5 \%$ on the same range of variation and did not affect the sizing of the system.

This study can be useful to companies, governments, and non-governmental organizations which install PVWPS. First, it allows evaluating the robustness of PVWPS sizing to borehole parameters change with the evolution of water resources. Second, it shows that only the static water level $H_{b, s}$ should be carefully estimated and monitored. This is good news since measuring $H_{b, s}$ with a water level meter is inexpensive. We recommend that the drawdown coefficients should be estimated thanks to the pumping tests that follow the drilling of the borehole. Then, the static water level $H_{b, s}$ should be monitored once a year to detect a possible overexploitation of the aquifer and adjust the peak power of the PV modules accordingly.

\section{Acknowledgements}

This work is supported by a public grant overseen by the French National research Agency (ANR) as part of the «Investissement d'Avenir» program, through the "IDI 2015" project funded by the IDEX Paris-Saclay, ANR-11IDEX0003-02.

\section{Bibliography}

[1] K. Lee, E. Brewer, C. Chirstiano, F. Meyo, E. Miguel, M. Podolsky, J. Rosa and C. Wolfram, "Barriers to Electrification for « Under Grid » Households in Rural Kenya", National Bureau of Economic Research, Cambridge, MA, w20327, Jul. 2014, DOI: 10.3386/w20327.

[2] L. Qoaider and D. Steinbrecht, "Photovoltaic systems: A cost competitive option to supply energy to off-grid agricultural communities in arid regions", Appl. Energy, vol. 87, no. 2, pp. 427-435, Feb. 2010, DOI: 10.1016/j.apenergy.2009.06.012.

[3] Y. Bakelli, A. Hadj Arab and B. Azoui, "Optimal sizing of photovoltaic pumping system with water tank storage using LPSP concept”, Sol. Energy, vol. 85, no. 2, pp. 288-294, Feb. 2011, DOI: 10.1016/j.solener.2010.11.023.

[4] Z. Girma, « Techno-economic analysis of photovoltaic pumping system for rural water supply in Ethiopia », Int. J. Sustain Energy, vol. 36, no. 3, pp. 277-295, Mar. 2017, DOI: 10.1080/14786451.2015.1017498.

[5] S. S. Chandel, M. Nagaraju Nail and R. Chandel, "Review of solar photovoltaic water pumping system technology for irrigation and community drinking water supplies”, Renew. Sustain. Energy Rev., vol. 49, pp. 1084-1099, Sept. 2015, DOI: 10.1016/j.rser.2015.04.083. 
[6] B. Singh, A. K. Mishra and R. Kumar, "Solar Powered Water Pumping System Employing Switched Reluctance Motor Drive", IEEE Trans. Ind. Appl., vol. 52, no. 5, pp. 3949-3957, Sept. 2016, DOI: 10.1109/TIA.2016.2564945.

[7] J. K. Kaldellis, E. Meidanis, D. Zafirakis, "Experimental energy analysis of a stand-alone photovoltaic-based water pumping installation", Appl. Energy, vol. 88, no. 12, pp. 4556-4562, Dec. 2011, DOI: 10.1016/j.apenergy.2011.05.036.

[8] S. Ould-Amrouche, D. Rekioua, and A. Hamidat, "Modelling photovoltaic water pumping systems and evaluation of their CO2 emissions mitigation potential," Appl. Energy, vol. 87, no. 11, pp. 3451-3459, Nov. 2010, DOI: 10.1016/j.apenergy.2010.05.021.

[9] X. Gao, J. Liu, J. Zhang, J. Yan, S. Bao, H. Xu and T. Qin "Feasibility evaluation of solar photovoltaic pumping irrigation system based on analysis of dynamic variation of groundwater table", Appl. Energy, vol. 105, pp. 182-193, May 2013.

[10] M. Benghanem, K. O. Daffallah, S. N. Alamri, and A. A. Joraid, "Effect of pumping head on solar water pumping system", Energy Convers. Manag., vol. 77, pp. 334-339, Jan. 2014, DOI: 10.1016/j.enconman.2013.09.043

[11] Z. Glasnovic and J. Margeta, "A model for optimal sizing of photovoltaic irrigation water pumping systems", Sol. Energy, vol. 81, no. 7, pp. 904-916, Jul. 2007, DOI: 10.1016/j.solener.2006.11.003.

[12] L. Narvarte and E. Lorenzo, "PV pumping analytical design and characteristics of boreholes", Sol. Energy, vol. 68, no. 1, pp. 4956, Jan. 2000, DOI: 10.1016/S0038-092X(99)00050-X.

[13] A. A. Ghoneim, "Design optimization of photovoltaic powered water pumping systems," Energy Convers. Manag., vol. 47, no. 11-12, pp. 1449-1463, Jul. 2006, DOI: 10.1016/j.enconman.2005.08.015.

[14] D. H. Muhsen, A. B. Ghazali, and T. Khatib, "Multiobjective differential evolution algorithm-based sizing of a standalone photovoltaic water pumping system", Energy Convers. Manag., vol. 118, pp. 32-43, Jun. 2016, DOI: 10.1016/j.enconman.2016.03.074.

[15] S. Meunier, M. Heinrich, L. Quéval, J. A. Cherni, L. Vido, A. Darga, P. Dessante, B. Multon, P. K. Kitanidis and C. Marchand, "A validated model of a photovoltaic water pumping system for off-grid rural communities", Appl. Energy, vol. 241, pp. 580-591, May 2019, DOI: 10.1016/j.apenergy.2019.03.035.

[16] C. V. Theis, "The relation between the lowering of the Piezometric surface and the rate and duration of discharge of a well using ground-water storage”, Trans. Am. Geophys. Union, vol. 16, no. 2, p. 519, 1935, DOI: 10.1029/TR016i002p00519

[17] P. E. Campana, H. Li, J. Zhang, R. Zhang, J. Liu, and J. Yan, "Economic optimization of photovoltaic water pumping systems for irrigation,” Energy Convers. Manag., vol. 95, pp. 32-41, May 2015, DOI: 10.1016/j.enconman.2015.01.066.

[18] J. Zhang, J. Liu, P. E. Campana, R. Zhang, J. Yan, and X. Gao, "Model of evapotranspiration and groundwater level based on photovoltaic water pumping system,” Appl. Energy, vol. 136, pp. 1132-1137, Dec. 2014, DOI: 10.1016/j.apenergy.2014.05.045.

[19] B. Bouzidi, "New sizing method of PV water pumping systems", Sustain. Energy Technol. Assess., vol. 4, pp. 1-10, Dec. 2013, DOI: $10.1016 /$ j.seta.2013.08.004.

[20] I. Odeh, Y. G. Yohanis, and B. Norton, "Influence of pumping head, insolation and PV array size on PV water pumping system performance", Sol. Energy, vol. 80, no. 1, pp. 51-64, Jan. 2006, DOI: 10.1016/j.solener.2005.07.009.

[21] A. Boutelhig, A.Hadjarab, and Y. Bakelli, "Comparison Study to Select an Optimum Photovoltaic Pumping System (PVPS) Configuration upon Experimental Performances Data of Two Different DC Pumps Tested at Ghardaïa Site”, Energy Procedia, vol. 6, pp. 769-776, 2011, DOI: 10.1016/j.egypro.2011.05.087.

[22] A. Acakpovi, F. F. Xavier, et R. Awuah-Baffour, "Analytical method of sizing photovoltaic water pumping system”, in 2012 IEEE $4^{\text {th }}$ International Conference on Adaptive Science \& Technology (ICAST), Kumasi, 2012, pp. 65-69, DOI: 10.1109/ICASTech.2012.6381067.

[23] S. Meunier, M. Heinrich, J. A. Cherni, L. Vido, B. Multon and P. K. Kitanidis, "Modelling and Optimal Sizing of Photovoltaic Water Pumping Systems - Sensitivity Analysis", Ecological Vehicles and Renewable Energies (EVER), 2019 Fourteenth International Conference, 2019, pp. 1-9

[24] Grundfos, "Performance curve of SQFlex 5A-7 motor-pump," URL: https://product-selection.grundfos.com/productdetail.product-detail.html?custid=GMA\&productnumber=95027342\&qcid=421916400 [accessed 12 May 2019].

[25] OmniInstruments, "DCX-22 SG Datasheet", URL:

https://www.omniinstruments.co.uk/fileuploader/download/download/?d=0\&file=custom\%2Fupload\%2F3726.pdf [accessed 12 May 2019].

[26] S. Meunier, L. Queval, A. Darga, P. Dessante, C. Marchand, M. Heinrich, J. Cherni, L. Vido, and B. Multon, "Influence of The Temporal Resolution of The Water Consumption Profile on Photovoltaic Water Pumping Systems Modelling and Sizing", in 7th Int. Conf. on Renewable Energy Research and Applications (ICRERA), pp. 494-499, Paris, France, Oct. 2018.

[27] C. E. Jacob, “Drawdown Test to Determine Effective Radius of Artesian Well”, Am. Soc. Civ. Eng., vol. 72 , May 1946.

[28] W. H. Bierschenk, "Determining well efficiency by multiple step-drawdown tests," International Association of Scientific Hydrology, 1963, URL: http://hydrologie.org/redbooks/a064/064043.pdf [accessed 12 May 2019].

[29] T. E. Reilly, L. Franke, and G. D. Bennett, "The principle of superposition and its application in ground-water hydraulics," US Geol. Surv., Open-File Report 84-459, 1987, URL: https://pubs.usgs.gov/of/1984/0459/report.pdf [accessed 12 May 2019 ]. 
[30] H. J. Seltman, "Experimental Design and Analysis", Chapter 6, Jul. 2018, URL: http://www.stat.cmu.edu/ hseltman/309/Book/Book.pdf. [accessed 24 September 2019]

[31] BBP Drilling, Borehole testing, 2019, URL: http://bbpdrilling.co.za/services/ [accessed 28 July 2019]

[32] Solinst, "Water Level Meter 101 Datasheet", URL: https://www.solinst.com/products/level-measurement-devices/101-waterlevel-meter/datasheet/ [accessed 12 May 2019].

[33] D. P. Dufresne, "Developing Better Regional Groundwater Flow Models with Effective Use of Step-Drawdown Test Results", Florida Water Resources Journal, vol. 63, no. 2, pp. 36-40., Feb. 2011

[34] I. Nazrul, A. Zahangir, and M. Minhaz, "Determination of Well Loss and Aquifer Loss of New Construction Deep Water Well at Artesian Aquifer in Khulna City, Bangladesh”, Recent Trends in Civil Engineering \& Technology, vol. 3, no. 1, pp. 8-13, 2013.

[35] C. J. Taylor and W. M. Alley, "Ground-water-level monitoring and the importance of long-term water-level data”, US Geological Survey, Circular no. 1217, Oct. 2001.

[36] G. van der Kamp and H. Maathuis, “Annual fluctuations of groundwater levels as a result of loading by surface moisture”, J. Hydrol., vol. 127, no. 1-4, pp. 137-152, Oct. 1991, DOI: 10.1016/0022-1694(91)90112-U.

[37] G. Strassberg, B. R. Scanlon, and M. Rodell, "Comparison of seasonal terrestrial water storage variations from GRACE with groundwater-level measurements from the High Plains Aquifer (USA)", Geophys. Res. Lett., vol. 34, no. 14, Jul. 2007, DOI: doi.org/10.1029/2007GL030139.

[38] D. Walker, N. Forsythe, G. Parkin, and J. Gowing, "Filling the observational void: Scientific value and quantitative validation of hydrometeorological data from a community-based monitoring programme", J. Hydrol., vol. 538, pp. 713-725, Jul. 2016, DOI: 10.1016/j.jhydrol.2016.04.062.

[39] V. Gholami, K. W. Chau, F. Fadaee, J. Torkaman, and A. Ghaffari, "Modeling of groundwater level fluctuations using dendrochronology in alluvial aquifers”, J. Hydrol., vol. 529, p. 1060-1069, Oct. 2015, DOI: 10.1016/j.jhydrol.2015.09.028.

[40] á. Rubio-Aliaga, J. M. Sánchez-Lozano, M. S. García-Cascales, M. Benhamou, and A. Molina-García, "GIS based solar resource analysis for irrigation purposes: Rural areas comparison under groundwater scarcity conditions”, Sol. Energy Mater. Sol. Cells, vol. 156, pp. 128-139, Nov. 2016, DOI: 10.1016/j.solmat.2016.06.045.

[41] T. W. Anderson, "Electrical-analog analysis of a ground-water depletion in central Arizona", Geological Survey Water-Supply Paper, 1968, DOI: 10.3133/wsp1860.

[42] J. S. Famiglietti, “The global groundwater crisis”, Nat. Clim. Change, vol. 4, no. 11, pp. 945-948, Nov. 2014, DOI: 10.1038/nclimate2425.

[43] JMP, "Drinking water, sanitation and hygiene service levels"; 2015, URL: https://washdata.org/data/household\#!/dashboard/2168 [accessed 12 May 2019].

[44] Y. Xu et B. Usher, "Groundwater Pollution in Africa”, Taylor \& Francis, 2006.

[45] D. Banks, T. Cosgrove, D. Harker, P. Howsam, et J. P. Thatcher, “Acidisation: borehole development and rehabilitation", Q. J. Eng. Geol. Hydrogeol., vol. 26, no. 2, pp. 109-125, May 1993.

[46] H. Timmer, J.-D. Verdel and A. G. Jongmans, "Well clogging by particles in Dutch well fields", J. -Am. Water Works Assoc., vol. 95, no. 8, pp. 112-118, Aug. 2003.

[47] Off-grid Europe, “Grundfos SQ Flex,” URL: https://www.off-grid-europe.com/accessories/pumps/grundfos/sq-flex [accessed 12 May 2019]

[48] E. André de La Fresnaye, "A financial and technical assessment of solar versus hand water pumping for off-grid area - the case of Burkina Faso", Master dissertation, Imperial College London, United Kingdom, 2018.

[49] C. Zhang, P. E. Campana, J. Yangx, et J. Yan, "Economic performance of photovoltaic water pumping systems with business model innovation in China", Energy Convers. Manag., vol. 133, pp 498-510, Feb. 2017, DOI: 10.1016/j.enconman.2016.10.069.

[50] I. Yahyaoui, A. Atieh, A. Serna, et F. Tadeo, "Sensitivity analysis for photovoltaic water pumping systems: Energetic and economic studies”, Energy Conv. Manag., vol. 135, pp. 402-415, Mar. 2017, DOI: 10.1016/j.enconman.2016.12.096.

[51] M. Montorfano, D. Sbarbaro, et L. Moran, "Economic and Technical Evaluation of Solar-Assisted Water Pump Stations for Mining Applications: A Case of Study “, IEEE Trans. Ind. Appl., vol. 52, no. 5, pp. 4454-4459, Sep. 2016, DOI: 10.1109/TIA.2016.2569415.

[52] TradingEconomics, "Discount rate in Burkina Faso", Jun. 2018, URL: https://tradingeconomics.com/burkina-faso/inflation-cpi [accessed 24 September 2019].

[53] K. Price, R. M. Storn, and J. A. Lampinen, "Differential Evolution: A Practical Approach to Global Optimization", Springer Science \& Business Media, 2006.

[54] G. Merei, C. Berger, et D. U. Sauer, "Optimization of an off-grid hybrid PV-Wind-Diesel system with different battery technologies using genetic algorithm”, Sol. Energy, vol. 97, pp. 460-473, Nov. 2013, DOI: 10.1016/j.solener.2013.08.016. 